\title{
Addressing Youth Unemployment in Bangladesh: A Policy Perspective
}

\author{
Mahir Musleh, Arunima Hassan, S M Saleh Reza
}

\begin{abstract}
In the quest for development, Bangladesh is at crossroads in meeting the challenge of productive employment creation. A mismatch between the skills acquired by youth and skills required by the employers is making it a daunting task for the youths to earn a living. To sustain economic growth, Bangladesh needs to focus on productive employment creation and decent work as a part of achieving the forthcoming Sustainable Development Goals (SDG) by the United Nations Organization. This paper takes a looks into the current youth unemployment scenario in Bangladesh and suggests policy measures to address the existing labor force peril.
\end{abstract}

Keywords - youth unemployment, job creation, productive employment, economic growth, labor surplus.

\section{Introduction}

The challenge of employment creation is nothing new for Bangladesh. In the post Millennium Development Goal (MDG) period, the government needs to devise the policies tailored to the proposed Sustainable Development Goals (SDG) by the United Nations Organization. The goal 8 of SDG focuses on promoting sustainable economic growth through productive employment creation and decent work. As a developing country, taking the decision based on unemployment rate only can lead to mis-targeted policies. While many of the developed countries were hard hit by recession, Bangladesh managed relatively well to safeguard its economy. The 2008-2009 recession has caused unemployment rates to rise $2.5 \%$ while youth unemployment rose to around $5.9 \%$. This paper will analyze the impact of youth unemployment on the economy of Bangladesh and suggest some policy measures to address this national challenge.

\section{Objective and Methodology}

The prime objective of the paper is to sketch out the threats posed by the youth unemployment in Bangladesh and state relevant policy prescription to tackle the problem. The paper mostly relies on secondary data collected from different government archives, journals, newspapers etc.

Mahir Musleh

McGill University

Montreal, Canada

Arunima Hassan

Institute of Business Administration, University of Dhaka

Dhaka, Bangladesh

S M Saleh Reza

Faculty, Daffodil International University

Dhaka, Bangladesh

\section{Youth Unemployment: Bangladesh Scenario}

Bangladesh has been experiencing acceleration in economic growth since 1990s. In the past decade the country's GDP growth has been $6 \%$ on average. In some years, GDP growth surpassed $6 \%$. But the overall performance on employment scenario fails to send an upbeat message for the economy. In a developing country like Bangladesh, one cannot simple reach a consensus about the labor market by merely looking at the unemployment rate. Bangladesh labor force survey of various years suggests that, the unemployment rate wavered between $4-5 \%$ from 1990 to 2000. The labor force survey 2010 estimates the current unemployment rate as $4.5 \%$ [1]. The previous three reports of labor force survey has reported unemployment rate as $4.3 \%$. Looking only at this statistics will definitely distract one from the real picture. A closer look at the statistics will point out that the youth unemployment rate in 2010 was $7.5 \%$ which is almost 1.5 times the overall unemployment rate.

International Labor Organization refers Youth unemployment to the share of the labor force aged 15-24 without work but available for and seeking employment. But, the Bangladesh Labor Force Survey considers 15-29 years as the age range to be considered as youth. The case of youth of unemployment requires particular attention because of various reasons. A mass of graduates enters into the workforce everywhere without being equipped with the required skillsets for the labor market of Bangladesh. The graduates face several challenges when they enter the labor force. In such situation, unemployment can cause long-term adverse effects on the life of the graduates which may hamper their employment experience in later life. The situation deteriorates during recession. Again, in early career, youths have a tendency to switch jobs which gives rise to frictional unemployment. Besides, during recession, firms have a tendency to lay off the youth labor force. Furthermore, the malignant effect of youth unemployment can transmit into economy which does not portend well.

\section{Impact of Youth Unemployment on Economy}

There are multifarious impacts of youth unemployment on the economy. The impact of youth unemployment can be divided into three categories: personal, social and national. First of all, the unemployed youth is deprived of the income he could have earned. In addition, there are also some long term debilitating consequences of such unemployment. Studies have shown that these unemployed youth in early life are more likely to be unemployed in the long run. Furthermore, in comparison to their peers who find jobs 
easily in early life, they earn less across their working life. [2]. Youth unemployment leads to income inequality which often leads to inequality in family income also. A family is usually worse off when it has to bear the expenses of an unemployed youth, which worsens a family's incomeexpenditure ratio. The adverse impact of youth unemployment transmits into the national economy in various ways. For example, the country misses out the revenue which could have been added to the economy. As a result of youth unemployment the country also lags behind the productive input that an employed youth could have added. Moreover, such phenomena implies that the countries' actual production is below the probable production level.

\section{v. Policy Measures to Tackle Youth Unemployment}

Reduction of youth unemployment will require actions through both the demand and the supply channels. Supply of labor encloses factors such as education, training and skill of labor pool etc. Demand of labor encloses factors such as subsidies, aid for startup of small and medium enterprises etc. Active Labor Market Policies include all kinds of steps and programs affecting both the supply and demand side of the labor market. Formation and implementation of such policies is not easy and policies have to have very shrewd and discretionary framework.

\section{A. Characteristics of a successful employment program}

A question of high significance is how successful have the youth employment program been. The answer to the question is actually not so easy. There has not been significant investigation and valuation of existing successful programs and therefore it is hard to judge the efficacy and efficiency of these programs. Nonetheless, a report of International Labor Organization [3] has outlined characteristics of a successful program. These characteristics are based on examples of successful programs though the measure of success is not mentioned. These characteristics can be followed to create well-functioning programs to boom the youth employment. Characteristics include the following [4]:

- Forming and materializing programs at the primary stage of unemployment

- Representing the necessities of the labor market in the outline of the programs

- Forming programs targeting particular groups and problems in the labor market

- Managing various programs (like training, aid to entrepreneurs, information availability etc) in a holistic manner

- Giving real world work experiences with the help of private sector

- Simultaneous actions of employers and labors

\section{B. Subsidy}

Subsidy stimulates the demand of labor in the market. Subsidies should be given to small and medium enterprises to hire unemployed youth of the economy. Appropriate funds for subsidies might be a problem. Subsidies can be funded by increasing the revenue or transferring of funds from unnecessary or/and less necessary programs to youth employment programs. There are various schemes through which subsidies work. The schemes are:

- Subsidizing a part of the wage expenses borne by the entrepreneurs

- Giving bonus to entrepreneurs to hire probationers

- Giving wage subsidies to entrepreneurs for hiring probationers regularly

- Encouraging and/or subsidizing entrepreneurs to hire long-term unemployed youth

- $\quad$ Subsidizing startups for small and medium enterprises

- Investing in small and medium enterprises that would lead to the employment of probationers (if government need/want returns from the investment then it is necessary to set a low rate of return otherwise new and young entrepreneurs will not be attracted to the scheme)

\section{Training and skill development}

Training and skill development have immense power to fuel the supply of labor. Training the unemployed youths even if they are skilled is critical. Unemployed youths have to be given necessary training so they can compete in the job market, but some skilled youths also need training as enough jobs on their field of specialty does not exist and thus these skilled youths needs training that would match the demands of the job market. Many youths in Bangladesh get education in one field and ultimately gets job of a totally different field and it shows that there is a mismatch of supply and demand of profession. Training is of vital importance because training is actually an investment in human capital. The training schemes can include:

- Concentrating more on the 'apprenticeship system' as apprenticeship aids an easy and smooth transition from the world of education to the world of profession. Countries (such as Germany, Denmark and Austria) that have extensive apprenticeship system also have lower youth unemployment rate [4].

- Training centers can be opened so that unskilled and/or low-skilled labor can attain higher skill and education to match the specific demands of the labor market and compete in it. There is a significant problem with this scheme however. By training labor to match the demand of the labor market, it would squeeze its diversity. This excessive demand of labor of certain professions will lead to lack of demand of certain subjects at the educational level and ultimately create an economy that severely lacks in knowledge and skills of some important professions. Therefore it is of high significance that the government should regulate this and encourage private firms to create a diversified 
demand for labor in the market. This will lead to creation of new and diversified enterprises.

- Trainers have to analyze the information and data of the labor market so that they can appropriately forecast its future demands. The trainers can then train the youths in accordance with the forecast.

- Training, in both private and public firms, should be continuous during the employment period to improve the skill of the youth, so that they can pace themselves with the developed countries' demands.

- With valid and insightful discretion, the training of the youths should be under existing schemes rather than newly created schemes.

\section{Public works program (PWP)}

Public works programs (PWPs) are schemes to invigorate the demand of labor and these programs mainly help low skilled workers to deal with short term economic shocks. Its success depends on a system's design and execution. PWPs are incumbent in Bangladesh as safety nets. These programs target the hard-core poor of Bangladesh [5] but do not necessarily affect the youth unemployment and especially do not target the educated youth. The PWPs in Bangladesh are there mainly to tackle seasonal food insecurity and unemployment problems of the hard-core poor [5].

New PWPs have to be designed and created targeting the youth sector of Bangladesh. Major design factors are mentioned in [6] and these factors can be used in the perspective of youths:

- Appropriately identifying the youth population in need of employment

- Choosing a wage that helps the youth to, at least, support themselves

- Establishing efficient implementation institutions

- Monitoring and correcting the system to avoid rationing, corruption, mismanagement and other execution flaws so that the targeted youth gets the jobs

\section{E. Information coordination}

Information gap in the labor market is not a new thing. Even in the era of such technological achievement we have not reached near the pinnacle of information flow expected of the labor market. Mismatch in information in the labor market slows down the process of employment and increases frictional unemployment. The youths are the new or recent entrants in this market. Establishment of information centers would act as an efficient information bridge between employers and prospective employees and could be a viable scheme to develop the flow of information in this market. These information centers should act as the following:

- Information centers should be set up with the collaboration of existing bureaus, departments and ministries like Bangladesh Bureau of Statistics (BBS), Bangladesh Bureau of
Educational Information \& Statistics (BANBEIS), The Department of Youth Development (DYD) and Ministry of Labor and Employment. This collective effort would bring into being a meticulous information system ready for the use of providing and advising.

- Information centers should facilitate the availability of detailed information of employers to prospective employees and vice versa.

- Information centers should advise prospective employees on job application, resume writing, job selection, and skills required for particular job etc.

- Information centers should be in both physical and digital form.

- Information centers must work with the media (television and radio channels) to create the widest possible network of information flow.

- Information centers have to have an up-to-date library of information.

Diagram 1. Step by Step process of Information Coordination

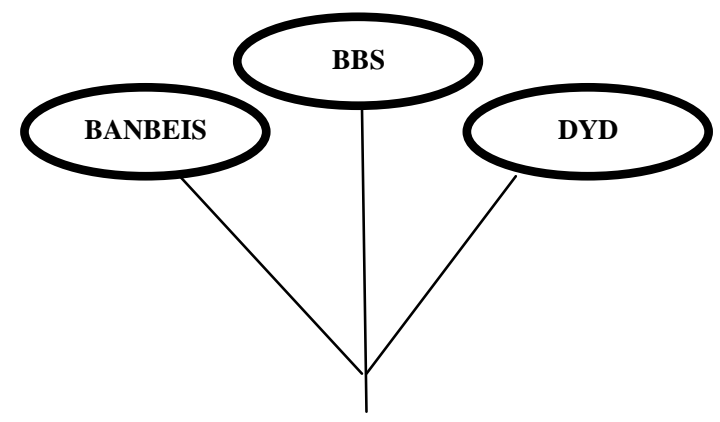

- Raw data collection including labor market supply side information such as number of graduates, their majors, skill levels etc.

- $\quad$ Also market demand side information from employers and government.

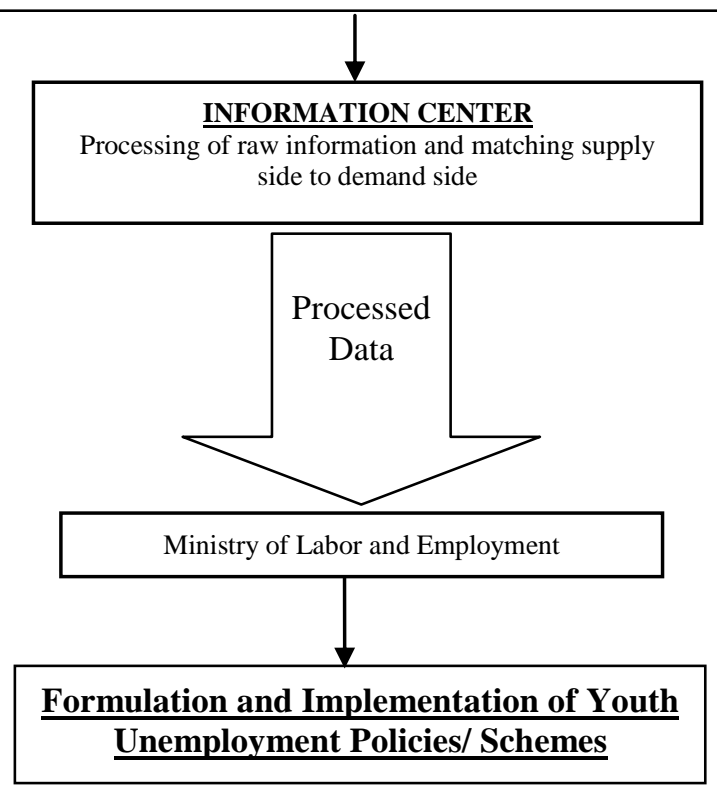




\section{F. Self-employment and entrepreneurship}

It is crucial that government of Bangladesh set up scheme/s to encourage self-employment and creation of small enterprises in the country. Local government can set up funds so that a scheme can be developed to aid the youths eager to be self-employed or to start a small business [4]. The schemes that would aid the youths are:

- Bringing experienced local entrepreneurs and managers to give the youths expert advice

- Creating a link between the youths and the market

- Helping the youths to get good loan deals for the startups of small enterprises

\section{vi. Conclusion}

Policies regarding the labor supply are very effective when the economy is at a high. When the economy is at a low these policies will not be very effective as labor demand is low. Policies are to be designed and created to invigorate both demand and supply of labor, and to compose an efficient and harmonious labor market. Though policies are to be designed in a holistic view, more concentration is to be given to the labor-intensive sector to reduce youth unemployment [4].

The youth constitutes a major part of the Bangladeshi population. It is of prime importance that policies are designed to aid the youth - who are usually the most innovative, creative and energetic people in the country - to create an immensely productive, creative and innovative workforce. Being the major part of the population, the youth greatly affects the social aspects of the country. Youth unemployment often leads to social distresses such as vandalism and mental hazard. Collective effort by institutions and authorities are necessary to solve the youth unemployment problem.

\section{References}

[1] Bangladesh Bureau of Statistics . (2010). Bangladesh Labor Force Survey. Dhaka: Bangladesh Bureau of Statistics .

[2] Von Wachter, Till, Jae Song, and Joyce Manchester, 2009, "LongTerm Earnings Losses Due to Mass Layoffs During the 1982 Recession: An Analysis Using U.S. Administrative Data from 1974 to 2004" (unpublished; New York: Columbia University).

[3] International Labor Organization (ILO) . (2011). Policy Options to Support Young Workers during Economic Recovery: Policy Brief . Geneva: ILO

[4] Islam, R. (2015). Unnoyon Bhabnay Kormosongsthan O Shromobazar. Dhaka: The University Press Limited .

[5] Solomon, S. D. (2006). Employment creation programmes: The international experience. Geneva : ILO.

[6] Zimmermann, L. (2014). Public works programs in developing countries have the potential to reduce porverty . IZA World of Labor.

[7] Kahn, Lisa B., 2010, "The Long-Term Labor Market Consequences of Graduating from College in a Bad Economy," Labor Economics, Vol. 17, No. 2, pp. 303-16.
About Author (s)

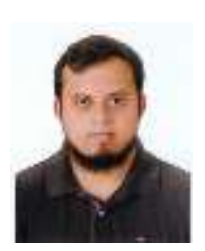

Mahir Musleh is currently pursuing his Masters in Economics in McGill University. His research interest includes Economic Growth, Unemployment etc.

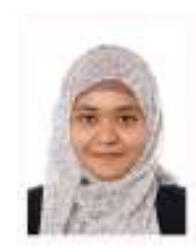

Arunima Hassan is currently studying at the Institute of Business Administration, Dhaka University. Her research interest includes Development Economics, Labor Economics and Game Theory.

S M Saleh Reza is currently teaching at Daffodil International University. He has completed his MBA with a major in Human Resources Management from North South University, Bangladesh. He is also a $\mathrm{PhD}$ researcher at Bangladesh University of Professionals. 